\title{
Immunotherapy of Mild Cognitive Impairment by $\omega-3$ Supplementation: Why Are Amyloid- $\beta$ Antibodies and $\omega-3$ Not Working in Clinical Trials?
}

\author{
Milan Fiala $^{\mathrm{a}, *}$, Lucas Restrepo ${ }^{\mathrm{b}}$ and Matteo Pellegrini ${ }^{\mathrm{a}}$ \\ ${ }^{a}$ Department of Molecular, Cell, and Developmental Biology, UCLA Life Sciences, Los Angeles, CA, USA \\ ${ }^{\mathrm{b}}$ Department of Neurology, UCLA School of Medicine, Los Angeles, CA, USA
}

\begin{abstract}
This article reviews the basic tenets of a clinical approach to effective immunotherapy of Alzheimer's disease (AD) in patients with mild cognitive impairment (MCI). Although one randomized controlled study in early MCI patients by fish-derived omega-3 fatty acids $(\omega-3)$ showed slowing of disease progression, large clinical trials with different products have failed to show cognitive effects. Macrophages of healthy subjects phagocytize and degrade amyloid- $\beta_{1-42}(A \beta)$ in the brain tissues, whereas macrophages of patients with $\mathrm{AD}$ and MCI are functionally defective. $\omega-3$ and $\omega$-3-derived specialized proresolving mediators (SPMs), such as resolvin D1, have powerful biochemical and immunological effects, which may repair the functions of MCI patients' macrophages in the brain's clearance of A $\beta$. Unfortunately, $\omega-3$ products on the market have a variable quality. Nutritional supplementation with a combination drink called Smartfish with an emulsion of $\omega-3$ and other fatty acids, antioxidants, 1,25-dihydroxy vitamin D3, and resveratrol improved the innate immune system of MCI patients by modulation of macrophage type to the pro-phagocytic M1-M2 type with an effective unfolded protein response against endoplasmic reticulum stress. Some MCI patients maintained their initial cognitive status for three years on Smartfish supplementation. Future randomized clinical trials should investigate the immune effects of $\omega-3,1,25$-dihydroxy vitamin D3, and SPMs on macrophage type, function, and biochemistry in parallel with cognitive effects.
\end{abstract}

Keywords: 1, 25-dihydroxy vitamin D3, amyloid- $\beta$, macrophage, mild cognitive impairment, omega-3, unfolded protein response

\footnotetext{
${ }^{*}$ Correspondence to: Milan Fiala, MD, Department of Molecular, Cell, and Developmental Biology, UCLA School of Life Sciences, Los Angeles, CA 90095, USA. Tel.: +1 310206 6392; E-mail:mfiala@ucla.edu.
}

\section{THE DISCOVERY OF DEFECTIVE PHAGOCYTOSIS, BLOOD-BRAIN BARRIER MONOCYTE MIGRATION, AND ABNORMAL INFLAMMATORY ACTIVATION OF ALZHEIMER'S DISEASE PATIENTS' MACROPHAGES}

We began an experimental study of Alzheimer's disease (AD) immunopathology in 1998 focusing on similar immunopathology in HIV-1 encephalitis and $\mathrm{AD}$, and on the physiology of monocyte 
migration across a human blood-brain barrier (BBB) model [1]. Microscopic features showed opening of gaps between endothelial cells and increasing monocyte transmigration fomented by cytokines and chemokines stimulated by $\mathrm{A} \beta$ in mononuclear cells in a snowball fashion. In this model, up to $12.6 \%$ monocytes transmigrated from the blood into the brain chamber in $24 \mathrm{~h}$. Thus, given the cerebral blood flow of $750 \mathrm{ml}$ per minute (approximately 1.5 billion monocytes per minute), 2,160 billion monocytes per $24 \mathrm{~h}$ are expected to transmigrate into the brain under the "Alzheimer-like" conditions of the model (clearly an overstatement in vivo). Even a fraction of this number would be sufficient to affect every neuron of the 100 billion neurons in the brain given the homing of monocytes on amyloid- $\beta(A \beta)$ in the neurons [2]. However, chemokine induction by $A \beta$ was heterogeneous between patients mirroring the heterogeneity observed in subsequent studies of patients and controls.

We hypothesized that macrophages, and possibly neutrophils, have opposite functions: 1) beneficial phagocytosis of $A \beta$, and 2) toxic inflammation, which are in imbalance in $\mathrm{AD}$ patients due to either very high (Group II patients) or very low (Group I patients) inflammatory activation [3]. In 2005, we observed that $\mathrm{AD}$ patients' macrophages are defective in $\mathrm{A} \beta$ phagocytosis (Fig. 1) and neutrophils overexpress HLA DR and COX-2 [4]. The relevant studies of macrophage phagocytic dysfunction and inflammatory activation by $\mathrm{A} \beta$ earned the Fiala laboratory the 2008 Alzheimer Award from the Journal of Alzheimer Disease. Macrophage dysfunction and abnormal (too high or too low) inflammatory status have been a consistent finding in almost all AD and mild cognitive impairment (MCI) patients in comparison to controls. In 2009, we developed and successfully tested in $\mathrm{AD}$ diagnosis a flow cytometric test based on defective $A \beta$ phagocytosis that separates mild $\mathrm{MCI}$ and $\mathrm{AD}$ patients from age-matched control subjects with a high cognitive function (i.e., University professors [5]).

\section{N-LINKED GLYCOSYLATION DEFECT IN PERIPHERAL BLOOD MONONUCLEAR CELLS}

An important insight into the biochemical mechanism of $\mathrm{AD}$ immunopathology was the
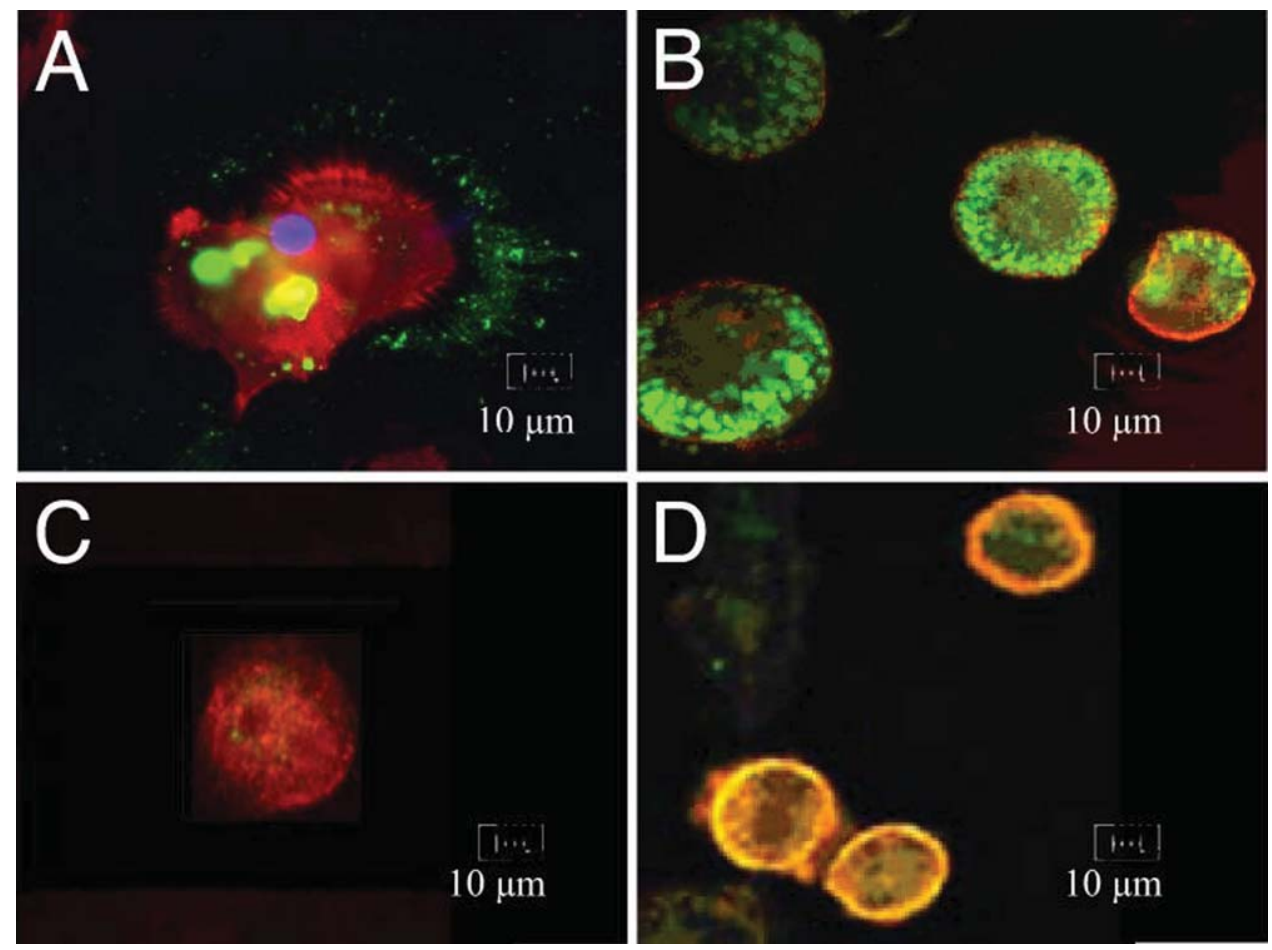

Fig. 1. Vigorous phagocytosis of FITC-A $\beta$ (green) by control macrophages (red) (A,B) but no phagocytosis or only surface binding without phagocytosis by AD macrophages (C,D) (from Fiala et al. [2]). 
discovery that the AD patients' macrophages have a defect in $A \beta$ phagocytosis (Fig. 2), which is related to transcriptional down regulation of the enzyme Mannosyl ( $\beta 1,4-)-G l y c o p r o t e i n ~ \beta-1,4-$ $\mathrm{N}$-Acetylglucosaminyltransferase (MGAT-III). Contrariwise, control macrophages are effective in phagocytosis and resist $A \beta$-induced apoptosis [2]. In our recent work on endoplasmic reticulum (ER) stress, we show that omega-3 fatty acids $(\omega-3)$ improve unfolded protein response (UPR) including the glycosyltransferase EXTL3 [6].

\section{MODULATION OF INNATE IMMUNITY IN AD AND MCI PATIENTS BY NATURAL SUBSTANCES}

Since 2009, we have been testing natural substances improving $\mathrm{A} \beta$ phagocytosis in $\mathrm{AD}$ patients: $1,25(\mathrm{OH})$-vitamin D3, curcuminoids, and the $\omega-3$, docosahexaenoic acid (DHA) and eicosapentaenoic acid (EPA) [7-10]. Armed with positive in vitro results, we did observation studies of MCI patients taking nutritional supplements with fish-derived $\omega$ 3 in combination with anti-oxidants, vitamin D3, and resveratrol (the Smartfish drink, Smartfish, Oslo, Norway). We noted robust immune improvement in macrophage function, and in some patients, in particular in the APOE $\varepsilon 3 / \varepsilon 3$ genotype patients, cognitive benefits $[5,10,11]$. We have not performed randomized, placebo-controlled, double blind studies, thus the cognitive benefits of supplementation by the Smartfish drink are anecdotal but of importance as a personalized medicine. The immune benefits of $\omega-3$ have a solid evidence in our studies (see below).

\section{IMMUNOPATHOLOGY OF AD}

In the early $2000 \mathrm{~s}$, we examined the AD brain by immunochemistry and immunofluorescence and showed demonstrable monocyte, and weak neutrophil and $\mathrm{CD} 8 \mathrm{~T}$ cell, transmigration across the $\mathrm{BBB}$ at the vessel wall; monocyte/macrophages invasion of neurons and $A \beta$ plaques; and uploading of $A \beta$ by macrophages $[12,13]$. The results suggested a hypothesis that $\mathrm{A} \beta$-induced chemokines attract monocytes [1] to invade the brain neuropil by disrupting tight junctions between endothelial cells in BBB. In the neuropil, macrophages are attracted by neuronal and astrocytic chemokines to the plaques and neurons, upload but are unable to degrade $A \beta$, and migrate to the vessel wall in congophilic vessels [13]. Our investigation in a model of BBB constructed with human endothelial cells and astrocytes suggested that 'fat macrophages" with $A \beta$ are stopped from emigration across BBB endothelia, die of apoptosis, and download $A \beta$ into congophilic vessels $[12,13]$.

Some neuropathologists consider the brain cells phagocytic for $A \beta$ according to their putative origin and certain surface markers as brain microglia or blood-borne macrophages with a possibility that both are present [14]. We support our impression of the dominant role of monocyte/macrophage migration into the $\mathrm{AD}$ brain by monocyte/macrophage migration into HIV-1 encephalitis brain and visible CD68-positive macrophage transmigration in the $\mathrm{AD}$ brain [12].

Microglia have multiple functions depending upon their activation state, which are alternatively beneficial or harmful [15]. Microglia through chemokines alert the peripheral innate immune system cells, monocyte/macrophages, of the danger to the brain, such as viruses (HIV-1, herpes simplex, and cytomegalovirus), and the pathogenic molecules $A \beta$ and P-tau. Chemokines attract monocyte/macrophages, CD8 T cells, and neutrophils for migration into the brain, as documented in HIV-1 encephalitis [16]. In AD patients, activated neutrophils expressing HLA-DR and COX-2 are present in the brain [4].

J. Nicoll's laboratory investigated the brain of $\mathrm{AD}$ patients treated by $A \beta$ vaccine immunization and showed co-localization of microglial markers HLA-DR, CD68, and the macrophage scavenger receptor A (MSR-A) around A $\beta$ plaques. The brain of immunized patients showed low plaque burden, $\mathrm{A} \beta$ in microglia, and resolution of tau-containing dystrophic neurites, but persistent amyloid angiopathy $[17,18]$. In addition, the results suggested that microglial lba-1 antigen was negatively associated with AD-type pathology. Conversely, macrophage proteins CD68 and MSR-A were positively associated with $\mathrm{AD}$-type pathology and impaired cognitive function [19]. These results may be related to the inability of AD patients' "fat" macrophages to emigrate from the brain and failure of $A \beta$ degradation [13].

Although the investigations in a mouse model also suggested that blood-borne monocyte penetrate BBB [20], the mode of macrophage entrance into the neuropil and relative roles of microglia and macrophages remain controversial in the mind of many investigators. We have reviewed this 

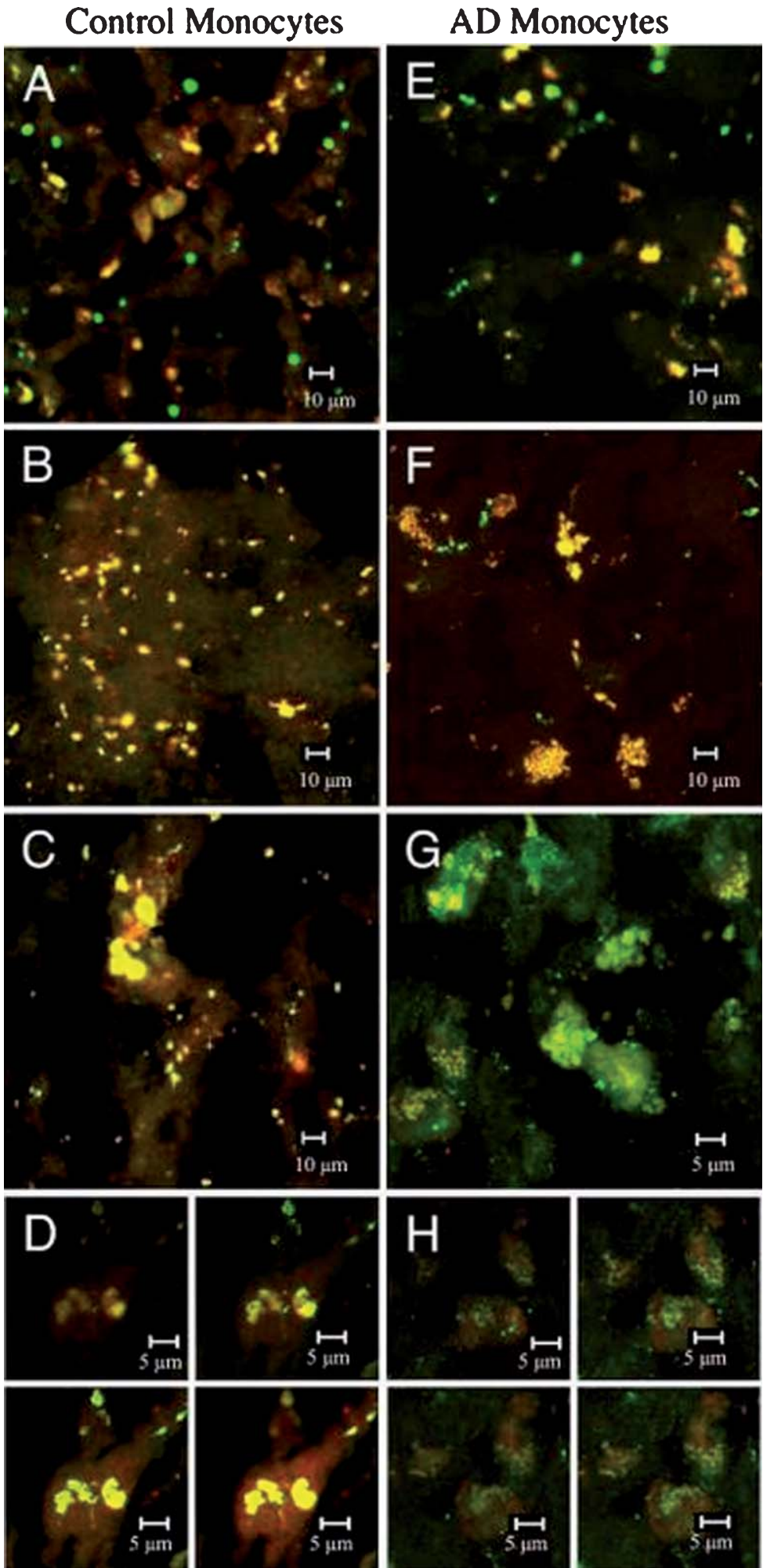

Fig. 2. Uploading of $A \beta$ (red) from $A D$ brain tissue after incubation for 2 days and 4 days with normal and AD monocytes (green). Note that normal monocytes bind to neurons and up load $\mathrm{A} \beta$ ((become golden); $\mathrm{AD}$ monocytes also bind to neurons but up load $\mathrm{A} \beta$ poorly and shrivel into apoptosis (from Fiala et al. [2]). 
important topic that has increasing attention [21]. Current emphasis is on imaging studies, which have low sensitivity in detecting macrophage/microglia activation, thus immunochemical investigation of the vessels in $\mathrm{AD}$ brain remains an important objective.

\section{PHYSIOLOGY AND PATHOPHYSIOLOGY OF AB CLEARANCE}

The physiology and pathophysiology of $A \beta$ transport across BBB have been examined in mouse model systems. The transvascular brain-to-blood transport across the $\mathrm{BBB}$ clears most of $\mathrm{A} \beta$ from brain, whereas the interstitial fluid bulk flow along perivascular spaces removes the remaining fraction of $-15 \%$ of $A \beta$ [22]. Future therapeutic studies may address the utility of modulation of the physiological transport in AD and MCI patients. Recent elucidation of the glymphatic system role in clearance of interstitial waste products driven by arterial pulsation revealed a physiological mechanism for clearance of soluble $A \beta$ during sleep [23], which strengthens the importance of a healthy sleep in brain homeostasis.

\section{IMMUNOPATHOLOGY OF A $\beta$ CLEARANCE IN AD BRAIN}

The role of $A \beta$ immune clearance has been extensively investigated in the genetically-uniform mouse models overexpressing the amyloid- $\beta$ protein precursor (A $\beta P P)$ with pathogenic mutations. However, these models do not express the human immune system of AD patients with defects in phagocytosis and their responses differ from human immune responses [24]. The models show the beneficial clearance either by microglia or toxic inflammation from $A \beta$ [25] without clarifying the complex balance between phagocytosis and inflammation. Bexarotene and other retinoid $\mathrm{X}$ receptor agonists improve transport of $A \beta$ from the brain in animal models (presumably by increasing APOE), but have not been clinically successful (as reported by J. Cummings from Lou Ruvo Center in Las Vegas).

We have investigated the immunopathology of the clearance of $\mathrm{A} \beta$ by monocyte/macrophages derived from peripheral blood mononuclear cells (PBMCs) in AD and MCI patients. We established that, contrary to the expectation from model systems, inflammatory activation of PBMCs in AD patients is divergent: the group II has inflammatory and the group I has non-inflammatory transcriptional responses [9]. The cell-mediated transport and degradation of $\mathrm{A} \beta$ by monocytes or microglia appear to be central to the clearance of insoluble $\mathrm{A} \beta$ in the $\mathrm{AD}$ brain $[13,26]$. Peripheral monocyte/macrophages appear to reflect the genuine $\mathrm{AD}$ immunopathology, as they have the phagocytic defect characteristic of AD (see above). For their janitorial function in the brain, macrophages have a vast armamentarium of responses, including inflammatory cytokines, chemokines, degradative enzymes, receptors, and growth factors. Our approach with $\omega-3$ supplementation has been successful in vivo to modulate macrophage phenotype from M1 inflammatory to an intermediate phenotype M1-M2 with optimal phagocytic function [11].

\section{CURCUMINOIDS, VITAMIN D3, AND $\omega-3$ FATTY ACIDS INCREASE A $\beta$ PHAGOCYTOSIS BY MACROPHAGES OF AD PATIENTS}

To increase $A \beta$ clearance, we have investigated natural substances that increase phagocytosis of $A \beta$ in vitro and may have transcriptional effects on $\mathrm{N}$-acetyl glucosaminyltransferase (a.k.a. MGAT-3) important for N-linked glycosylation. Our early studies in 2009-2012 involved curcumin and vitamin D3; the studies since 2013 involve $\omega-3$ fatty acids and specialized pro-resolving mediators resolvins and maresins [27]. We are studying the combinations of curcuminoids, vitamin D3, with $\omega-3$ fatty acids to identify any subgroups of patients specifically benefitting from these substances in combination.

\section{Role of curcuminoids}

In a study of $20 \mathrm{AD}$ patients and 20 controls, we identified two groups, Type 1 with low $M G A T-3$ transcription, and Type 2 with high MGAT-3 transcription. Importantly, curcumin improved $A \beta$ phagocytosis only in Type 1 patients, but not in Type 2 patients. Type 1 patients had worse prognosis than Type 2 patients [28].

\section{Role of vitamin D3}

In the same study [28], vitamin D3 improved $\mathrm{A} \beta$ phagocytosis in both Type 1 and Type 2 
patients. 1alpha,25-dihydroxyvitamin D3 (1,25D3) interacted with curcuminoids to stimulate $A \beta$ clearance by macrophages [7]. Thus, 1,25D 3 is indicated for all $\mathrm{AD}$ patients. $1,25 \mathrm{D} 3$ promotes phagocytosis by genomic and non-genomic signaling [8]. The action of 1,25 D3 requires vitamin D nuclear receptor and the protein disulfide isomerase receptor.

\section{Role of $\omega-3$ fatty acids and specialized pro-resolving mediators}

The anti-inflammatory and pro-resolving SPMs include resolvins, protectins, and maresins derived in vivo by transcellular synthesis from $\omega-3$ fatty acids. SPMs have powerful effects in various model systems [29]. Resolvin D1 binds the chemokine receptor GFPR32. We observed that both 1,25D3 and resolvin $\mathrm{D} 1$ (RvD1) retune the balance between $\mathrm{A} \beta$ phagocytosis and inflammation and have synergistic activities [9] (Fig. 3).

\section{Mechanisms of 1,25 D3 and curcumin improving A $\beta$ phagocytosis}

In Type 1 patients, both ligands potentiate 4,4'-Diisothiocyano-2,2'-stilbenedisulfonic acid (DIDS)-sensitive chloride channel $\mathrm{ClC} 3$ and calcium signaling and both support phagocytosis, whereas in Type 2 patients only $1,25 \mathrm{D} 3$ is effective [8].

\section{Mechanisms of $\omega-3$ and specialized pro-resolving mediators in the brain}

DHA attenuates $A \beta$ secretion in cytokine-stressed human neural cells, an effect accompanied by the formation of NPD1 [30]. NPD1 is one of the SPMs with beneficial immune effects in inflammatory and degenerative conditions [29]. Interestingly, another mediator LXA4 had reduced concentration in the AD cerebrospinal fluid (CSF) and hippocampus. LXA4 and RvD1 levels in CSF correlated with Mini-Mental State Examination (MMSE) scores. [31]. Supplementation with AT-RvD1 prevented memory loss in an animal model of post-surgical cognitive decline [32]. The effects of $\omega-3$ in the brain are complex [33] involving effects on membrane fluidity and modification of membrane rafts, thus affecting cell signaling [34]. A relationship exists between the $\omega-3$ erythrocyte concentration and higher regional perfusion on the brain SPECT [35].

\section{CONTROVERSIES REGARDING $\omega-3$ EFFECTS: QUALITY OF THE SUPPLEMENT}

Anti-inflammatory health benefits of $\omega$-3 have been recognized since epidemiological studies showed cardiovascular benefits of traditional fish diets in natives in Greenland, Alaska, and Japan. Clinical studies have shown benefits of $\omega$-3 supplementation in rheumatoid arthritis, asthma, and ulcerative colitis [36]. However, recent epidemiological studies of aging populations have not shown that $\omega-3$ supplementation prevents cognitive decline and brain atrophy. A study of 295 mild to moderate AD patients randomized to algal DHA or placebo did not show slowing of cognitive and functional decline by DHA [37]. A recent study of 1,680 elderly subjects with memory complaints included multiple sites with a randomized controlled design involving multicomponent intervention with polyunsaturated fatty acids and lifestyle changes [38]. The participants took two capsules of either placebo or $400 \mathrm{mg}$ DHA and no more than $112.5 \mathrm{mg}$ EPA. Despite these interventions, no significant effects on cognitive decline were observed in any arm of this study over 3 years. The report, however, did not show the quality of the $\omega-3$ supplement. It is clear that not all $\omega-3$ products on the market are equal. It has been reported that $50 \%$ of the products exceed the voluntary recommended levels for markers of oxidation [39]. Furthermore, the elderly patients in the study were not diagnosed with MCI.

In our experience, high quality fish oil used in Smartfish drink protected by antioxidants has superior effects in vitro on $\mathrm{A} \beta$ phagocytosis in comparison to generic fish oil. Thus, the negative effects of supplementation in some clinical studies could be related to the use of fish oil without antioxidant protection. We observe that the immune and cognitive results of $\omega-3$ supplementation are dependent on the APOE genotype, stage of the disease, and poorly understood individual factors, including immunosuppressive conditions, infections, surgeries, and lifestyle, all of which typical clinical trials do not evaluate. The immune and cognitive results do not show a linear improvement or a linear decline but include up and down turns. Therefore, the question "why are $\omega-3$ not working in clinical trials" may be related to the quality of the supplement, selection of patients, neuropsychological testing, and medical and neurological histories. We have recently reviewed the effects of $\omega-3$ in the AD brain and the immune system $[21,27]$. 


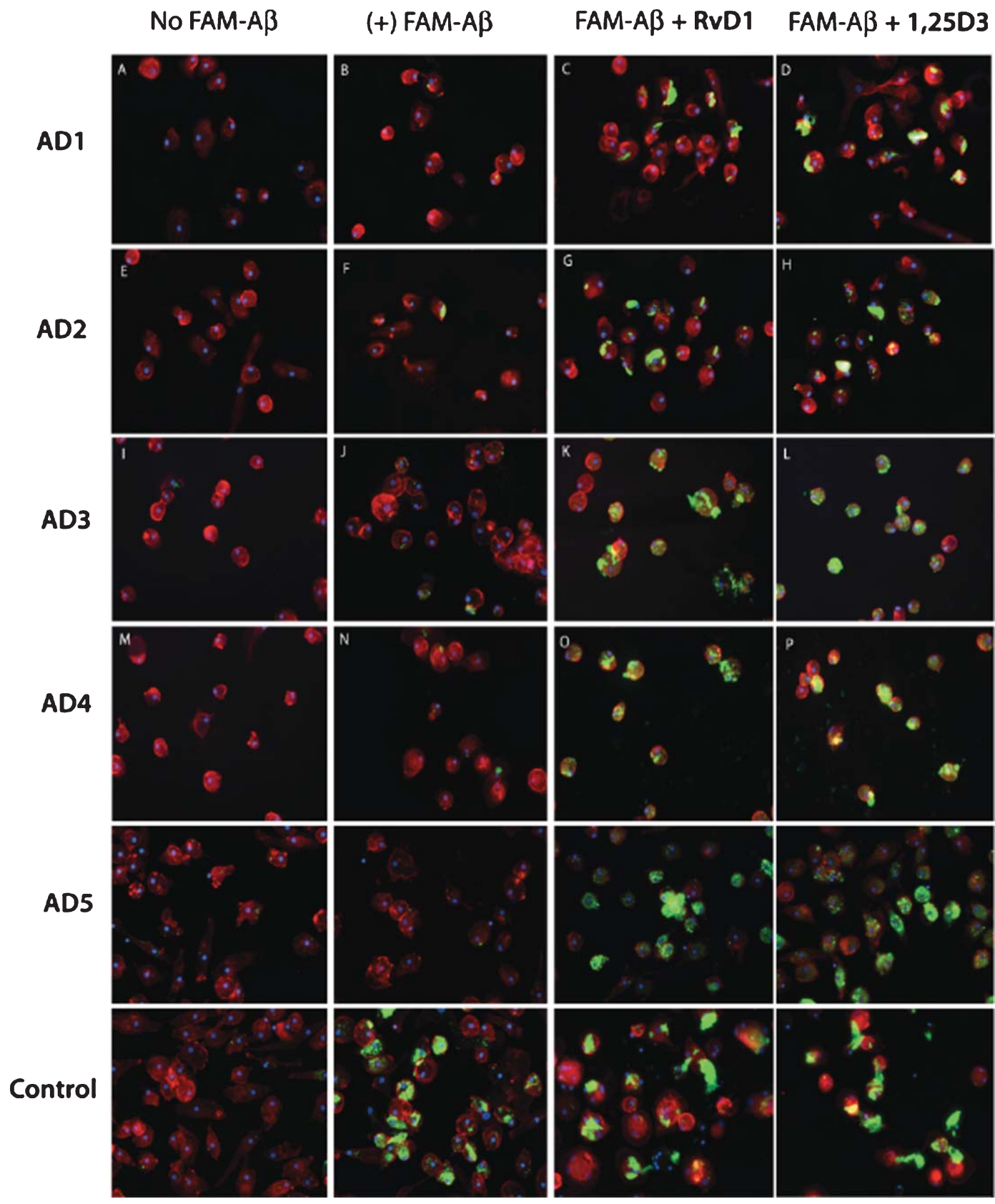

Fig. 3. 1,25D3 and RvD1 treatments recover FAM-A $\beta$ (green) phagocytosis by macrophages of AD1- to AD5 patients. Control subject's macrophages phagocytize $A \beta$ without any treatment.

\section{CONTROVERSIES REGARDING $\omega-3$ EFFECTS: PATIENT SELECTION AND NEUROPSYCHOLOGICAL TESTING}

A randomized, double-blind, placebo-controlled trial showed that in a subgroup with very mild cognitive dysfunction (MMSE >27 points), MMSE decline rate was reduced in the $\omega-3$ fatty acid- treated group compared with the placebo group [40]. Two studies, however, recently reported negative effects of $\omega-3$ despite treatment-induced increases in DHA levels in the CSF in the Alzheimer's Disease Cooperative Study (ADCS) [37], and increased DHA levels in erythrocytes in the Multidomain Alzheimer Preventive Trial (MAPT) [38]. 
The ADCS used supplementation by algal DHA. The study size was calculated to detect a $33 \%$ difference in the rate of decline of the Alzheimer's Disease Assessment Scale-Cognitive subscale (ADAS-Cog). ADAS-Cog has traditionally been the standard primary outcome measure for $\mathrm{AD}$ trials, with the assumption that a 4-point change at 6 months is clinically meaningful. A concern with ADAS-Cog is that it may not detect clinically important effects, which is one of the reasons why most clinical trials use several other indicators of clinical progression. For instance, a drop in ADAS-Cog score did not correlate well with other estimates of clinical decline in a study using open-label donepezil [41]. Another potential criticism, inherently applicable to most $\mathrm{AD}$ trials, is the practice of lumping all patients together without regard to specific biomarkers, including presence of cerebral amyloid angiopathy as an entry criterion and APOE genotype. Although the ADCS investigators were mindful of biomarkers such as MRI volumetrics, they did not measure other surrogates of therapeutic response, such as changes in CSF and blood amyloid concentration or CSF tau. Interestingly, non-APOE $\varepsilon 4$ allele carriers in the ADCS trial treated with DHA had significantly lower ADAS-Cog and MMSE decline as compared to placebo (ADAS-Cog: 6.23 versus 10.11 points, $p=0.03$; MMSE: -3.36 versus $-5.12, p=0.03$ ). Finally, although the study was designed with an attrition rate of $20 \%, 28 \%$ of DHA-treated patients and $24 \%$ of placebo-treated controls dropped out of the study.

Although MAPT used fish-derived $\omega-3$, its results are difficult to contextualize, as the enrolled population was heterogeneous with vague criteria, and its primary efficacy outcome was rather unusual. The studied population was elderly persons with "spontaneous" memory complains, limitation in one instrumental activity of daily living, or "slow gait speed". The differential diagnosis of such constellation of symptoms is vast. For instance, only 72 of 1,680 patients had amyloid PET scan; of these, 56 had a negative scan, indicating that a substantial number of enrolled subjects did not have AD. Similarly, only 304 subjects had APOE genotyping. The primary outcome measure was a change in a composite Z-score of 4 cognitive tests: Free and total recall from the Free and Cued Selective Reminding Test, some MMSE orientation items, the Digit Symbol Substitution Test score from the Wechsler Adult Intelligence Scale-Revised, and the Category Naming Test, a 2-min category fluency test naming animals. Not many studies use this particular outcome measure, and its clinical relevance is unknown.

Ideally, a clinical trial should enroll individuals with very similar clinical and genetic (APOE) characteristics and a strong characterization of the underlying disease process related to the $A \beta$ brain amyloidosis. In addition, it is unlikely that a single intervention will yield a particular therapeutic effect in a disease process as complicated as AD. These imperatives require testing a large patient sample in a randomized, double-blind, placebo controlled study.

In our small pilot studies, we have defined the outcome by immunological and molecular tests not included in large studies. Given the epidemiological and in vitro evidence of health benefits by $\omega-3$ and 1,25D3, we have tested in MCI patients in vivo and in PBMCs in vitro the effects $\omega-3$ supplementation by a drink with fish $\omega$-3, antioxidants, vitamin D3, and resveratrol called Smartfish-RES (Smartfish, Oslo, Norway) [10, 11]. In vivo, $\omega-3$ supplementation increased macrophage phagocytosis and regulated mRNA transcription of inflammatory genes toward the physiological state in the "Goldilocks zone": in a non-inflammatory group, it increased the transcription, whereas in the inflammatory group, it decreased the transcription [10]. In a follow-up study, $\omega-3$ modulated the macrophage phenotype into the intermediate M1M2 phenotype and increased the MMSE rate of change in the APOE $\varepsilon 3 / \varepsilon 3$ group by 2.2 points per year [11]. Recently, we have shown that a mechanism of $\omega-3$ immune effects involves an increase of appropriate UPR response to ER stress in macrophages [6].

\section{CONCLUSIONS}

The $A \beta$ hypothesis, which has been a productive hypothesis for AD therapy, has been at the center of a controversy in view of the lack of efficacy of $\mathrm{A} \beta$ antibodies on cognitive state despite clearance of $\mathrm{A} \beta$. Although the in vitro effects of $\omega-3$ have not yet been translated into a successful therapy in vivo, nutritional supplementation by $\omega-3$ was associated with a recovery of innate immunity with parallel cognitive stabilization in some patients, in particular those with the APOE $\varepsilon 3 / \varepsilon 3$ genotype. Therefore, future clinical trials of immune therapies should include detailed immunologic and molecular studies to identify the best therapy for each patient. 


\section{ACKNOWLEDGMENTS}

The studies with $\omega-3$ were supported by donations from Smartfish AS to M.F. Smartfish AS was not involved in the design, analysis, interpretation of the data, or the decision to submit the manuscript for publication.

Authors' disclosures available online (http://j-alz. com/manuscript-disclosures/17-0579r1).

\section{REFERENCES}

[1] Fiala M, Zhang L, Gan X, Sherry B, Taub D, Graves MC, Hama S, Way D, Weinand M, Witte M, Lorton D, Kuo YM, Roher AE (1998) Amyloid-beta induces chemokine secretion and monocyte migration across a human blood-brain barrier model. Mol Med 4, 480-489.

[2] Fiala M, Liu PT, Espinosa-Jeffrey A, Rosenthal MJ, Bernard G, Ringman JM, Sayre J, Zhang L, Zaghi J, Dejbakhsh S, Chiang B, Hui J, Mahanian M, Baghaee A, Hong P, Cashman J (2007) Innate immunity and transcription of MGAT-III and Toll-like receptors in Alzheimer's disease patients are improved by bisdemethoxycurcumin. Proc Natl Acad Sci U S A 104, 12849-12854.

[3] Fiala M, Cribbs DH, Rosenthal M, Bernard G (2007) Phagocytosis of amyloid-beta and inflammation: Two faces of innate immunity in Alzheimer's disease. J Alzheimers Dis 11, 457-463.

[4] Fiala M, Lin J, Ringman J, Kermani-Arab V, Tsao G, Patel A, Lossinsky AS, Graves MC, Gustavson A, Sayre J, Sofroni E, Suarez T, Chiappelli F, Bernard G (2005) Ineffective phagocytosis of amyloid-beta by macrophages of Alzheimer's disease patients. J Alzheimers Dis 7, 221-232; discussion 255-262.

[5] Avagyan H, Goldenson B, Tse E, Masoumi A, Porter V, Wiedau-Pazos M, Sayre J, Ong R, Mahanian M, Koo P, Bae S, Micic M, Liu PT, Rosenthal MJ, Fiala M (2009) Immune blood biomarkers of Alzheimer disease patients. J Neuroimmunol 210, 67-72.

[6] Olivera H, Lam L, Dang J, Jiang W, Rodriguez F, Rigali E, Weitzman S, Porter V, Rubi L, Morselli M, Pellegrini M, Fiala M (2017) Omega-3 fatty acids increase the unfolded protein response and improve amyloid-beta phagocytosis by macrophages of mild cognitive impairment patients. FASEB J 31, 4359-4369.

[7] Masoumi A, Goldenson B, Ghirmai S, Avagyan H, Zaghi J, Abel K, Zheng X, Espinosa-Jeffrey A, Mahanian M, Liu PT, Hewison M, Mizwicki M, Cashman J, Fiala M (2009) 1alpha,25-dihydroxyvitamin D3 interacts with curcuminoids to stimulate amyloid-beta clearance by macrophages of Alzheimer's disease patients. J Alzheimers Dis 17, 703-717.

[8] Mizwicki MT, Menegaz D, Zhang J, Barrientos-Duran A, Tse S, Cashman JR, Griffin PR, Fiala M (2012) Genomic and nongenomic signaling induced by 1 alpha, $25(\mathrm{OH}) 2$ vitamin D3 promotes the recovery of amyloid-beta phagocytosis by Alzheimer's disease macrophages. J Alzheimers Dis 29, 51-62.

[9] Mizwicki MT, Liu G, Fiala M, Magpantay L, Sayre J, Siani A, Mahanian M, Weitzman R, Hayden EY, Rosenthal MJ, Nemere I, Ringman J, Teplow DB (2013) 1alpha,25dihydroxyvitamin D3 and resolvin D1 retune the balance between amyloid-beta phagocytosis and inflammation in Alzheimer's disease patients. J Alzheimers Dis 34, 155-170.

[10] Fiala M, Halder RC, Sagong B, Ross O, Sayre J, Porter V, Bredesen DE (2015) omega-3 Supplementation increases amyloid-beta phagocytosis and resolvin D1 in patients with minor cognitive impairment. FASEB J 29, 2681-2689.

[11] Famenini S, Rigali EA, Olivera-Perez HM, Dang J, Chang MT, Halder R, Rao RV, Pellegrini M, Porter V, Bredesen D, Fiala M (2017) Increased intermediate M1-M2 macrophage polarization and improved cognition in mild cognitive impairment patients on omega-3 supplementation. FASEB J 31, 148-160.

[12] Fiala M, Liu QN, Sayre J, Pop V, Brahmandam V, Graves MC, Vinters HV (2002) Cyclooxygenase-2-positive macrophages infiltrate the Alzheimer's disease brain and damage the blood-brain barrier. Eur J Clin Invest 32, 360-371.

[13] Zaghi J, Goldenson B, Inayathullah M, Lossinsky AS, Masoumi A, Avagyan H, Mahanian M, Bernas M, Weinand M, Rosenthal MJ, Espinosa-Jeffrey A, de Vellis J, Teplow DB, Fiala M (2009) Alzheimer disease macrophages shuttle amyloid-beta from neurons to vessels, contributing to amyloid angiopathy. Acta Neuropathol 117, 111-124.

[14] Boche D, Perry VH, Nicoll JA (2013) Review: Activation patterns of microglia and their identification in the human brain. Neuropathol Appl Neurobiol 39, 3-18.

[15] Perry VH, Nicoll JA, Holmes C (2010) Microglia in neurodegenerative disease. Nat Rev Neurol 6, 193-201.

[16] Persidsky Y, Ghorpade A, Rasmussen J, Limoges J, Liu XJ, Stins M, Fiala M, Way D, Kim KS, Witte MH, Weinand M, Carhart L, Gendelman HE (1999) Microglial and astrocyte chemokines regulate monocyte migration through the blood-brain barrier in human immunodeficiency virus-1 encephalitis. Am J Pathol 155, 1599-1611.

[17] Zotova E, Holmes C, Johnston D, Neal JW, Nicoll JA, Boche D (2011) Microglial alterations in human Alzheimer's disease following Abeta42 immunization. Neuropathol Appl Neurobiol 37, 513-524.

[18] Zotova E, Bharambe V, Cheaveau M, Morgan W, Holmes C, Harris S, Neal JW, Love S, Nicoll JA, Boche D (2013) Inflammatory components in human Alzheimer's disease and after active amyloid-beta42 immunization. Brain 136, 2677-2696.

[19] Minett T, Classey J, Matthews FE, Fahrenhold M, Taga M, Brayne C, Ince PG, Nicoll JA, Boche D, Mrc C (2016) Microglial immunophenotype in dementia with Alzheimer's pathology. J Neuroinflammation 13, 135.

[20] Simard AR, Soulet D, Gowing G, Julien JP, Rivest S (2006) Bone marrow-derived microglia play a critical role in restricting senile plaque formation in Alzheimer's disease. Neuron 49, 489-502.

[21] Fiala M, Kooij G, Wagner K, Hammock B, Pellegrini M (2017) Modulation of innate immunity of patients with Alzheimer's disease by omega- 3 fatty acids. FASEB $J \mathbf{3 1}$, 3229-3239.

[22] Nelson AR, Sagare AP, Zlokovic BV (2017) Role of clusterin in the brain vascular clearance of amyloid-beta. Proc Natl Acad Sci USA 114, 8681-8682.

[23] Xie L, Kang H, Xu Q, Chen MJ, Liao Y, Thiyagarajan M, O’Donnell J, Christensen DJ, Nicholson C, Iliff JJ, Takano T, Deane R, Nedergaard M (2013) Sleep drives metabolite clearance from the adult brain. Science 342, 373-377.

[24] Seok J, Warren HS, Cuenca AG, Mindrinos MN, Baker HV, Xu W, Richards DR, McDonald-Smith GP, Gao H, 
Hennessy L, Finnerty CC, Lopez CM, Honari S, Moore EE, Minei JP, Cuschieri J, Bankey PE, Johnson JL, Sperry J, Nathens AB, Billiar TR, West MA, Jeschke MG, Klein MB, Gamelli RL, Gibran NS, Brownstein BH, Miller-Graziano C, Calvano SE, Mason PH, Cobb JP, Rahme LG, Lowry SF, Maier RV, Moldawer LL, Herndon DN, Davis RW, Xiao W, Tompkins RG, Inflammation, Host Response to Injury LSCRP (2013) Genomic responses in mouse models poorly mimic human inflammatory diseases. Proc Natl Acad Sci USA 110, 3507-3512.

[25] ElAli A, Rivest S (2015) Microglia in Alzheimer's disease: A multifaceted relationship. Brain Behav Immun 55, 138150 .

[26] Nicoll JA, Barton E, Boche D, Neal JW, Ferrer I, Thompson P, Vlachouli C, Wilkinson D, Bayer A, Games D, Seubert P, Schenk D, Holmes C (2006) Abeta species removal after abeta42 immunization. J Neuropathol Exp Neurol 65, 10401048.

[27] Fiala M, Terrando N, Dalli J (2015) Specialized proresolving mediators from omega-3 fatty acids improve amyloid-beta phagocytosis and regulate inflammation in patients with minor cognitive impairment. J Alzheimers Dis 48, 293-301.

[28] Fiala M, Mahanian M, Rosenthal M, Mizwicki MT, Tse E, Cho T, Sayre J, Weitzman R, Porter V (2011) MGAT3 mRNA: A biomarker for prognosis and therapy of Alzheimer's disease by vitamin D and curcuminoids. J Alzheimers Dis 25, 135-144.

[29] Serhan CN, Chiang N, Dalli J (2015) The resolution code of acute inflammation: Novel pro-resolving lipid mediators in resolution. Semin Immunol 27, 200-215.

[30] Lukiw WJ, Cui JG, Marcheselli VL, Bodker M, Botkjaer A, Gotlinger K, Serhan CN, Bazan NG (2005) A role for docosahexaenoic acid-derived neuroprotectin D1 in neural cell survival and Alzheimer disease. J Clin Invest 115, 27742783.

[31] Wang X, Zhu M, Hjorth E, Cortes-Toro V, Eyjolfsdottir H, Graff C, Nennesmo I, Palmblad J, Eriksdotter M, Sambamurti K, Fitzgerald JM, Serhan CN, Granholm AC, Schultzberg M (2015) Resolution of inflammation is altered in Alzheimer's disease. Alzheimers Dement 11, 40-50 e41-42.

[32] Terrando N, Gomez-Galan M, Yang T, Carlstrom M, Gustavsson D, Harding RE, Lindskog M, Eriksson LI (2013) Aspirin-triggered resolvin D1 prevents surgery-induced cognitive decline. FASEB J 27, 3564-3571.
[33] Dyall SC (2015) Long-chain omega-3 fatty acids and the brain: A review of the independent and shared effects of EPA, DPA and DHA. Front Aging Neurosci 7, 52.

[34] Williams JA, Batten SE, Harris M, Rockett BD, Shaikh SR, Stillwell W, Wassall SR (2012) Docosahexaenoic and eicosapentaenoic acids segregate differently between raft and nonraft domains. Biophys $J \mathbf{1 0 3}, 228-237$.

[35] Amen DG, Harris WS, Kidd PM, Meysami S, Raji CA (2017) Quantitative erythrocyte omega-3 EPA plus DHA levels are related to higher regional cerebral blood flow on brain SPECT. J Alzheimers Dis 58, 1189-1199.

[36] Yates CM, Calder PC, Ed Rainger G (2014) Pharmacology and therapeutics of omega-3 polyunsaturated fatty acids in chronic inflammatory disease. Pharmacol Ther 141, 272-282.

[37] Quinn JF, Raman R, Thomas RG, Yurko-Mauro K, Nelson EB, Van Dyck C, Galvin JE, Emond J, Jack CR Jr, Weiner M, Shinto L, Aisen PS (2010) Docosahexaenoic acid supplementation and cognitive decline in Alzheimer disease: A randomized trial. JAMA 304, 1903-1911.

[38] Andrieu S, Guyonnet S, Coley N, Cantet C, Bonnefoy M, Bordes S, Bories L, Cufi MN, Dantoine T, Dartigues JF, Desclaux F, Gabelle A, Gasnier Y, Pesce A, Sudres K, Touchon J, Robert P, Rouaud O, Legrand P, Payoux P, Caubere JP, Weiner M, Carrie I, Ousset PJ, Vellas B, Group MS (2017) Effect of long-term omega 3 polyunsaturated fatty acid supplementation with or without multidomain intervention on cognitive function in elderly adults with memory complaints (MAPT): A randomised, placebo-controlled trial. Lancet Neurol 16, 377-389.

[39] Jackowski SA, Alvi AZ, Mirajkar A, Imani Z, Gamalevych Y, Shaikh NA, Jackowski G (2015) Oxidation levels of North American over-the-counter n-3 (omega-3) supplements and the influence of supplement formulation and delivery form on evaluating oxidative safety. J Nutr Sci $\mathbf{4}$, e30.

[40] Freund-Levi Y, Eriksdotter-Jonhagen M, Cederholm T, Basun H, Faxen-Irving G, Garlind A, Vedin I, Vessby B, Wahlund LO, Palmblad J (2006) Omega-3 fatty acid treatment in 174 patients with mild to moderate Alzheimer disease: OmegAD study: A randomized double-blind trial. Arch Neurol 63, 1402-1408.

[41] Rockwood K, Fay S, Gorman M, Carver D, Graham JE (2007) The clinical meaningfulness of ADAS-Cog changes in Alzheimer's disease patients treated with donepezil in an open-label trial. BMC Neurol 7, 26. 